\title{
Digital Transformation in the Context of the European Union and the Use of Digital Technologies as a Tool for Business Sustainability
}

\author{
Diana Bednarčíková ${ }^{1, *}$, Radka Repiská ${ }^{2}$ \\ ${ }^{1}$ University of Economics in Bratislava, Faculty of Business Management, Department of Information \\ Management, 85235 Bratislava, Slovakia \\ ${ }^{2}$ University of Economics in Bratislava, Faculty of Business Management, Department of Business \\ Economy, 85235 Bratislava, Slovakia
}

\begin{abstract}
The potential of digitalization, digital transformation and digital technologies is important for environmental, economic and social sustainability in businesses and can be applied in various industries. In this scientific article, main author's aim is to examine the green digital transformation in a theoretical generalization, then in the context of the European Union and to examine the use of digital technologies in the field of sustainable development in selected companies in the world. We used explanatory general theoretical methods. In the literature review, we defined the main concepts related to digital transformation, mapped the digital transformation in the context of the European Union and highlighted the link between sustainability and digital technologies. Examples of the implementation of sustainable technologies in various companies and compliance with sustainability are found in the results of the work and discussion. At the end of the scientific article, we propose definitions: Green digital transformation is the implementation of digitalization and interaction of green technologies into business processes, activities, products and models, when the company becomes environmentally sustainable. Green technology represents the integration and subsequent use of digital technologies to innovate business processes and are used in the field of sustainable environmental development of the organization.
\end{abstract}

\section{Introduction}

The global pandemic of the coronavirus COVID-19 has confirmed the importance of digitization in the world and many businesses have been forced to digitally transform in order to create their business and enterprise activities. Digital transformation in companies represents a change of business processes towards efficiency, innovation, competitiveness, sustainability and overall economic growth of the company. The application of digitization,

\footnotetext{
* Corresponding author: diana.bednarcikova@euba.sk
} 
digitalization, the use of ICT (Information and Communication Technologies) and the interaction of digital technologies in business: processes, activities, models lead to the digital transformation of the business and may ultimately become completely digital. Any digital technologies are: Artificial Intelligence, Cloud Computing, Internet of Things, Robotics Process Automation, etc. referred to as Industry 4.0 (Fourth Industrial Revolution) technologies, they are widely used in all areas of society and connect the physical, digital and biological worlds. The development of digital technologies is key to environmental sustainability, as well as serving as a catalyst for companies, for example, where digital technologies: reduce pollution and emissions, improve energy efficiency, degrade the environment, lead to better resource allocation and efficiency.

The paper consists of four main parts. The next section describes the literature review consisting of three main parts (overview of definitions in the field of green and digital transformation, the European context and sustainability of digital technologies). The second section defines research goals and methodology, the third section clarifies the results of the review on specific companies and the fourth part closes paper with the main implications of the review and sets the direction for future research.

The aim of the scientific article is to examine the green digital transformation in a theoretical generalization, then in the context of the European Union and to examine the use of digital technologies in the field of sustainable development in selected companies in the world.

\section{Literature review}

\subsection{Definition of digitalization, digital transformation, digital technologies and sustainability}

Digitalization is identified as the most significant technological trend for society and business [1]. Digitalization precedes digitization, which is a technical process for converting analog information streams to digital bits 1 with 0 with discrete and discontinuous values [2,3]. Bican and Brem [4] state that digitization refers to a technical process in which analog information is transformed by coding and programming by information technology lenses into a digital format, and this process represents the integration of digital technologies into everyday life. Digitalization is defined by Linkov et al. [5] as increased interconnection and networking of digital technologies to improve communication, services and trade between people, organizations and things. According to Bican and Brem [4], digitalization is a socio-technological process of applying digitization techniques - digitization in broader social and institutional contexts that create the infrastructure of digital technologies. Digitalization is the impact of digitization on society and refers to the application of digital technologies that bring about changes in societies between businesses and in the business markets caused by digitization [3]. Digitalization consists in introducing digital technological innovations into existing (organizational, industrial, social) systems in a way that changes their functioning [6].

Digital transformation is a profound change and accelerates business activities, process, competencies, models in order to take full advantage of changes and opportunities in digital technology and its impact on society in a strategic and priority way [4]. Digital transformation refers to unprecedented disruptions to society, industry, organizations stimulated by advances in digital technologies such as: Artificial Intelligence, Big Data Analytics, Cloud Computing and The Internet of Things [7]. The digital transformation of business models is transforming consumer preferences and consumption as industries 
introduce digital technologies to increase their competitiveness in order to change customer relationships, internal processes and value prepositions [3].

The first prerequisite for digital transformation is digital technologies that transform the way environmental sustainability issues are measured and managed [7]. Digital technologies are the technologies of the fourth industrial revolution, also called Technologies Industry 4.0. Digital technology under Bican and Brem [4] is the basis for innovation in platforms and digital environments, and these technologies are highly interconnected, enabling and increasing information processing capacity. Feroz, Zo \& Chiravuri [7] further state that digital technologies offer organizations unique opportunities to develop new environmental business models or to adopt digital technologies to incorporate environmentally sustainable practices into existing business models. Digital technologies are forcing companies to reimagine their customer value offerings as new social and mobile applications, analytics, the Internet of Things, artificial intelligence, biometrics, blockchain, cloud and edge computing, and many other advances allow them to deliver value in ways that simply were not possible [8].

\subsection{Green Digital Transformation in the European Context}

Digitalization has significant social and environmental implications, and various organizations in the world (e.g.: OECD, UN, EU) have considered the need for institutions and practices in the field of sustainable management. The European Union also contributes to the promotion and surveillance of sustainability and digital transformation in the world and in business through its legal frameworks, policies, programs and instruments.

On 4 December 2019, the European Environment Agency (EEA) published its report "The European Environment - State and Outlook 2020" (SOER 2020) and its results make us think. Current environmental, climate and sustainability challenges have reached unprecedented scale and urgency and effectiveness, and immediate and coordinated action and systemic solutions. The Union's environmental policy has brought significant benefits in recent decades without affecting the EU's long-term competitiveness, with the acquis focusing even more on long-term visions, targets and strategic framework policies effectively reducing environmental pressures over the last few years.

However, the loss of biodiversity, the deterioration of ecosystem services, climate change and its impacts, as well as the unsustainable use of resources, environmental pollution and related risks to human health and living conditions, nature, ecosystems and the economy, require further decisive action in the EU and worldwide. The European Commission responded to these challenges and adopted the European Green Deal on 11 December 2019 - a new growth strategy for dual, green and digital transformation, which aims to transform the Union into a fair and prosperous society with a competitive, climateneutral and resource-efficient economy. A Regulation of the European Parliament and of the Council (EU) enshrines the goal of the EU to become the first climate-neutral continent by 2050 to protect, preserve and enhance the EU's natural capital and protect citizens' health and well-being from environmental risks and impacts.

According to the SOER 2020 report "The European Environment - State and Outlook 2020", the coming years are a unique opportunity for the Union to demonstrate its leadership in sustainability and to address the urgent challenges in this area that require systemic solutions [9]. The changes in the global climate and ecosystems that can be observed since the 1950 s are unparalleled in recent decades to millennia. The world's population has tripled since 1950, while the number of people living in cities has quadrupled. With the current growth model, environmental pressures are expected to increase further, with direct and indirect harmful effects on human health and well-being. 
This is especially true for the sectors with the greatest impact on the environment - food, mobility, energy, as well as infrastructure and buildings.

On 10 March 2020, the European Commission laid the foundations for an industrial strategy that should support the dual transformation to a green and digital economy, increase the global competitiveness of EU industry and strengthen Europe's open strategic autonomy. Updating the $\mathbf{2 0 2 0}$ Industrial Strategy: towards a stronger Single Market for Europe's recovery included a list of measures to support the green and digital transformation of EU industry, many of which have already been adopted or launched. However, the pandemic drastically affected the speed and extent of this transformation. Companies that strive for sustainability and digitization are likely to be among the leaders of tomorrow.

The European Green Deal forms the basis for the Recovery Instrument proposed by the European Commission on 27 May 2020 "Next Generation EU", which supports investment in key green sectors needed to build resilience and create growth and jobs in a fair and inclusive society. A mechanism to support recovery and resilience, which, together with the Union budget for 2021-2027, will drive the Union's economic recovery from the coronavirus crisis, while making this recovery lasting and ensuring prosperity for future generations in the transition to a sustainable way of life and advancing digital transformation.

On 27 May 2020, the European Commission published the report „The EU budget powering the recovery plan for Europe" where is proposing to harness the full potential of the EU budget. Next Generation EU of $€ 750$ billion as well as targeted reinforcements to the long-term EU budget for 2021-2027 will bring the total financial firepower of the EU budget to $€ 1.85$ trillion. The funds raised from the Next Generation EU instrument will be invested in three pillars which are shown in Figure 1:

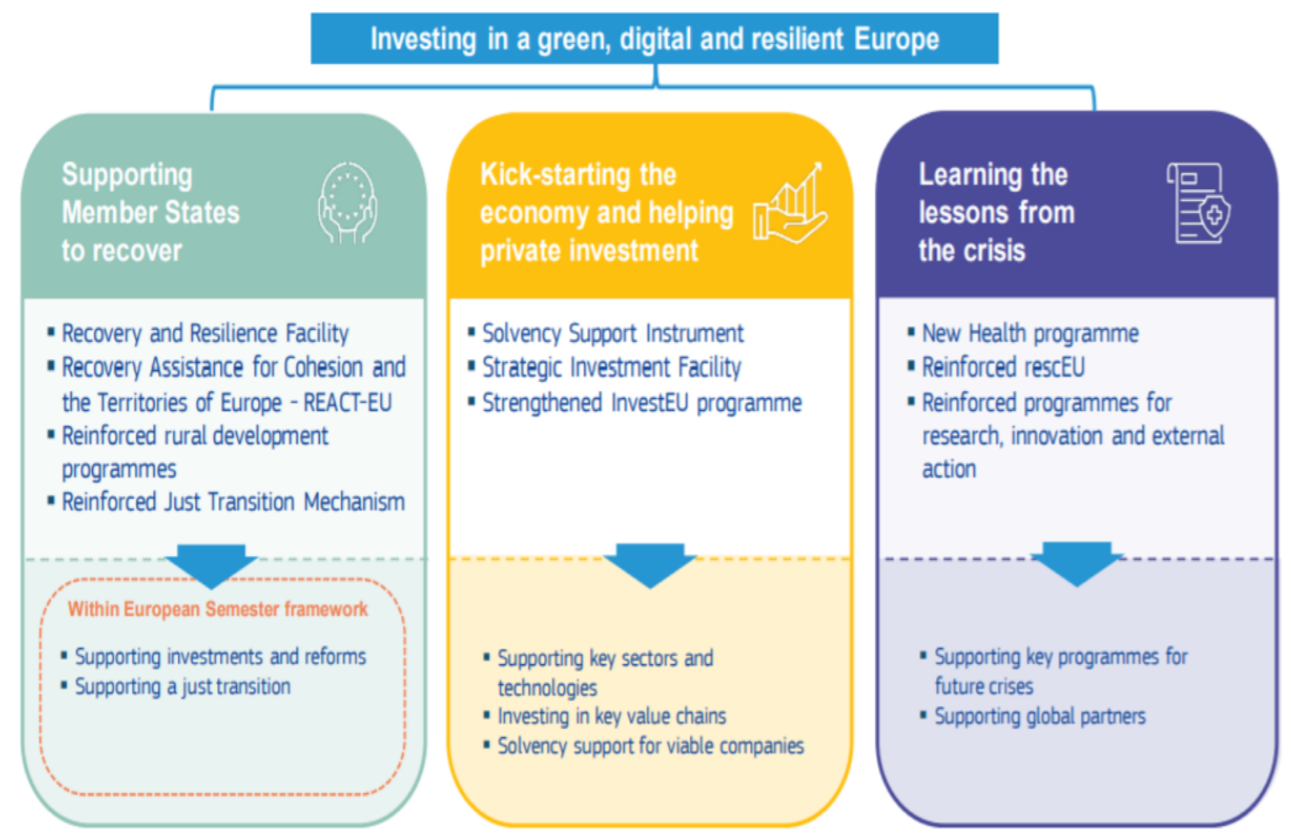

Fig. 1. Next Generation EU: investing in a greener and more digital EU (3 pillars).

The new package will be reflected in particular in the field of green and digital transformation, with the aim of modernizing the economies of the Member States as well as strengthening the businesses affected by the COVID-19 pandemic. Relaunching the 
economy does not mean going back to the status quo before the crisis, but bouncing forward. We must repair the short-term damage from the crisis in a way that also invests in our long-term future.

All of the money raised through Next Generation EU will be channelled through EU programmes in the revamped long-term EU budget to the activities shown in the Table 1.

Table 1. The policy fundamentals of the recovery.

\begin{tabular}{|c|c|}
\hline $\begin{array}{l}\text { A. The European Green } \\
\text { Deal as the EU's } \\
\text { recovery strategy }\end{array}$ & 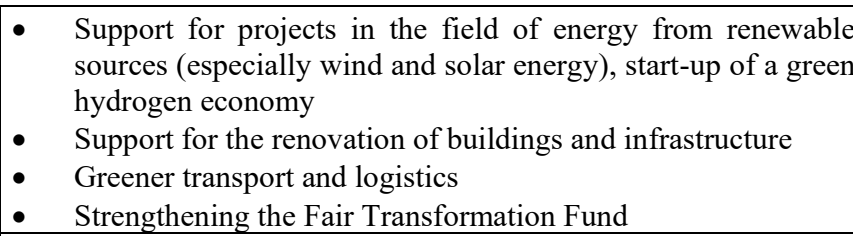 \\
\hline $\begin{array}{l}\text { B. Strengthening the } \\
\text { Single Market and } \\
\text { adapting it to the } \\
\text { digital age }\end{array}$ & $\begin{array}{l}\text { - } \text { Investing in bigger and better connectivity (5G network) } \\
\text { - } \quad \text { Stronger industrial and technological presence in strategic } \\
\text { sectors (Artificial Intelligence, Cyber Security, } \\
\text { Supercomputers, Cloud and others) } \\
\text { - } \quad \text { Building a real data economy } \\
\text { - Increased cyber resilience }\end{array}$ \\
\hline $\begin{array}{l}\text { C. A fair and inclusive } \\
\text { recovery for all }\end{array}$ & 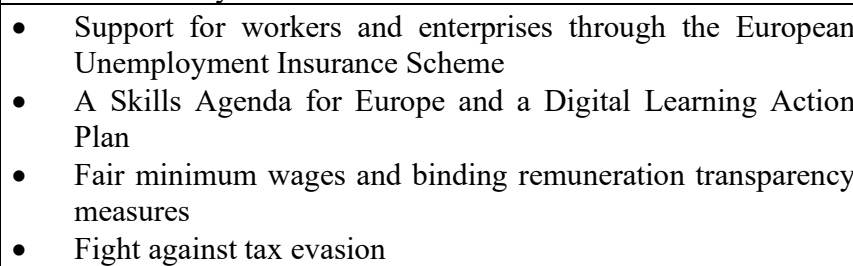 \\
\hline
\end{tabular}

The majority of proposed partnerships aim to accelerating the transitions towards a climate-neutral, circular society and economy, and achieving the Sustainable Development Goals (SDG). Consequently, many will team up with the private sector to decarbonise the energy, mobility and steel sectors, or with Member States to provide solutions for the sustainable management of resources (e.g. water, soil) and preserve biodiversity. Others aim at building greater resilience of Europe's health care systems and industry, including by ensuring the EU's technological leadership and autonomy in critical areas, such as Smart Networks and Services, Artificial Intelligence, Data and Robotics and Photonics. Built4People, Driving Urban Transitions, Clean Energy Transition, and the EIT KICS are also relevant for the New European Bauhaus.

In ministerial declaration „A Green and Digital Transformation of the EU“ states that digital technologies are an important part of the EU's green growth strategy (EU Green Deal) [10]. Businesses, governments and NGOs need to work together to implement new technologies, innovative solutions and progressive public policies that reflect our shared vision of a more prosperous and sustainable future. Therefore, we can say that we are proud of the 26 large international companies that formed the European Green Digital Coalition "EGDC" and signed the Declaration in Support of the EU's Green and Digital Transformation, which was launched on Digital Day 2021 on 19 March as a virtual event. The Member States of the European Union, together with Norway and Iceland, have signed a declaration on accelerating the use of green digital technologies for the benefit of the environment, thereby committing themselves to key digital initiatives.

As part of the creation of a EGDC in fewer of their companies, the directors of 26 international companies have committed themselves to take action in areas such as:

- Invest in the development and deployment of greener digital technologies and services that are more energy and material efficient. 
- Develop methods and tools to measure the net impact of green digital technologies on the environment and climate by joining forces with NGOs and relevant professional organizations.

- International companies, together with representatives of other sectors, work together to develop recommendations and guidelines for the green digital transformation of these sectors that are beneficial to the environment, society and the economy.

The European Green Digital Coalition will not only help the technology sector to become more sustainable, circular and zero polluters, but will also support the sustainability goals of other priority sectors such as energy, transport, agriculture and construction, while contributing to an innovative, inclusive and resilient society [10-13].

\subsection{Sustainability of digital technologies}

Sustainability consists of three dimensions such as: environmental, economic and social and form the so-called sustainable triangle. The dimensions are interrelated and are defined according to Wut et al. as follows: environmental sustainability (environmental) is defined as "the continuous preservation of the ecosystem and its functions; economic sustainability means the lasting ability of the economic system to meet all human needs and social sustainability promotes the well-being of all people; such as access to food, medicine, education and recreation [14]. Overall, sustainability aims to protect our natural environment and human health, while promoting the balance of ecosystems and innovation, and economic behavior must be improved in the interests of human and environmental sustainability; for this purpose, technological innovation is a support tool [15]. Wut et al. also defines digital sustainability, which in the narrower sense is the sustainable use of digital resources (data and computer files, source codes and technologies) - the ability of a digital system to be constantly maintained, resp. Renew and, more broadly, represent organizational activities that seek to achieve the goals of sustainable development through the creative introduction of technologies that: create, use, transmit or obtain electronic data [14].

Digitalization increases the likelihood of social and environmental sustainability challenges and threats, including the carbon footprint associated with increased demand for electricity generation, cybersecurity weaknesses and social disparities due to the growing gap in access to ICT, commonly referred to as digitization. The "digital divide" [5]. Without the transformation of existing businesses, the economic and environmental challenges of the future cannot be addressed in a sustainable way, and therefore resource optimization for more sustainable businesses is driven by digital technologies that form the basis of digital innovation in platforms and digital environments [4]. Digital technologies (Artificial Intelligence, Big Data, Internet of Things, Social Media Analytics, Cloud Computing, and Mobile Technologies) are increasingly used to improve environmental sustainability, transform various aspects of environmental sustainability and enable transformations in various areas of environmental sustainability such as: pollution control, waste management, sustainable production and urban sustainability [7]. Digital technologies support the development of value proposals that combine environmental, social and economic value and can make a significant contribution to the goals of sustainable development [16].

In the COVID-19 era, Industry 4.0 technologies are also expected to accelerate the transition to sustainable business processes and to achieve sustainable development, especially as a priority of economic recovery, which will have to address biodiversity loss, climate change and promote circular economy principles [17]. Industry 4.0 and digital technology, respectively - Artificial Intelligence (AI) is associated with positive and negative impacts on humans and the planet, and much attention is currently being paid to 
the analysis and evaluation of these impacts [18]. Digitalization supports the development of Artificial Intelligence (AI) and, thanks to it, computer science enables the creation of intelligent machines (algorithms and software) that function and react like humans [5]. Demartini, Evans and Tonelli state that companies currently rely on AI, IoT and big data analysis to implement sustainable business practices that include reducing carbon emissions and minimizing other environmental impacts [19].

\section{Research objectives and methodology}

The aim of the scientific article is to examine the green digital transformation in a theoretical generalization, then in the context of the European Union and to examine the use of digital technologies in the field of sustainable development in selected companies in the world.

The starting point for the elaboration of a scientific article was: study, analysis, synthesis and comparison of foreign literature in the form of: books, professional articles, studies, surveys, laws, policies, etc. Deduction and induction methods were also used.

The research subjects were: the European Union and business entities such as: Amazon, Carbon Tracker, Google, IBM, Microsoft, Ørsted, Patagonia, Walmart and Xcel Energy. Due to the scope of the scientific article, it was not possible to examine all the theoretical definitions and areas of the use of digital technologies in the business processes of selected companies.

\section{Results and discussion}

PWC company estimates that using artificial intelligence for environmental applications could contribute up to $\$ 5.2$ trillion to the global economy by 2030 [20]. The use of Artificial Intelligence (AI) for environmental applications in four sectors such as agriculture, energy, transport and water is expected to have the potential to increase global GDP to $4.4 \%$ by 2030 (the estimate for Europe is $5.4 \%$ ). At the same time, the application of AI leverage could reduce global greenhouse gas (GHG) emissions by 4\% in 2030, equivalent to $2.4 \mathrm{Gt} \mathrm{CO} 2 \mathrm{e}$ - equivalent to the annual emissions of Australia, Canada and Japan by 2030 . While improving productivity, AI could create 38.2 million net new jobs in the global economy that would offer more skilled occupations as part of this transition.

Examples of the implementation of sustainable technologies in various companies and compliance with sustainability are as follows:

- Amazon - uses Artificial Intelligence to meet its long-term goal of powering its global infrastructure with $100 \%$ renewable energy. This includes its AWS cloud platform.

- Carbon Tracker - a think-tank focused on combating climate change, uses AI to monitor emissions from coal-fired power plants using satellite imagery. Using satellite data, they help drive investments toward lower footprint businesses.

- Google - uses the AI model to reduce the energy load of its data centers - the Google Cloud Platform resource-hungry and reduce the energy cost of cooling by $40 \%$.

- IBM - uses AI for better weather forecasting, making their forecasts 30\% more accurate. This helps renewable energy companies better manage their power plants, maximize renewable energy production and reduce carbon emissions.

- Microsoft - is committed to being carbon-negative by 2030, using Artificial Intelligence to run huge public data centers (Cloud Deals) called Microsoft Azure. Microsoft's cloud computing has already enhanced energy efficiency and reduced 
material waste. Increased availability of serverless and open-source software minimizes cooling, ventilation, and air conditioning in fewer data centers. The addition of power management to Microsoft products has enabled intelligent power consumption on end devices such as monitors and hard drives.

- Orsted - a provider of wind technology and bioenergy from Denmark and in 2020 this company ranked as the most sustainable company in the world.

It was to work with Microsoft, where together they would successfully face environmental challenges. Ørsted's biggest effort is to build a "completely green world" with a 100\% carbon-free energy supplement by 2025 . The company is limiting oil and coal-based activities in favor of clean energy systems. Ørsted owns more than a thousand offshore wind turbines equipped with sensors that continuously generate valuable data. Microsoft's advanced predictive analytics and technology is part of Ørsted's digital strategy for sustainable data and time-saving data transformation.

- Patagonia - a sustainable clothing company uses organic materials, sells worn and reworked clothing and organic accessories. The company also provides global funding through online banking and runs the online blog The Cleanest Line, where articles are devoted to environmental crises and solutions. Patagonia, which is consciously aware, has implemented a number of innovations in the company's management, such as: recycled building materials with laminated windows that prevent overheating, solar panels with photosensors and motion detectors, LED lighting, new heating, ventilation and air conditioning systems controlled by intelligent network. In addition, the company has a central Artificial Intelligence workstation that automatically manages all operating systems from indoor to outdoor irrigation. Bathrooms and toilets are equipped with water control sensors. The landscape and plants around the buildings are also selected and designed to reduce water consumption. Workers are advised to use electric cars and then receive financial compensation for commuting by bicycle or public transport.

- Walmart - one of the largest retail companies is deploying digital transformations multiple times, working to eliminate waste and energy consumption and ensure supply chain management. First and foremost, the numerous built-in IoT sensors and shelf scanning robots are proving to be sustainable in terms of energy savings and customer experience. In e-retail, it allows its customers to shop at home, reducing transport utilization and $\mathrm{CO} 2$ emissions. In 2018, the company patented the idea of a robobee - an unmanned drone for pollinating crops equipped with cameras and sensors. This tool also makes it possible to detect agricultural problems and gain sufficient control over the Walmart food supply chain, which in turn minimizes food waste.

- Xcel Energy - a coal-fired and nitrous oxide-emitting energy company, uses Artificial Intelligence to better predict energy consumption patterns and adapt its operating systems, significantly increasing efficiency $(\sim 20 \%)$.

According to Bican and Brem (2020), business models need to be analyzed in terms of their future readiness and impact on sustainability, as both economic and environmental sustainability are interrelated challenges for businesses that cannot be addressed in isolation.

\section{Conclusion}


The current problem in companies is outdated technologies that are not efficient and then the lack of information about the impact of technologies on the environment, so companies are not environmentally friendly and unknowingly damage the environment.

Digitalization has a long-term high potential in companies and can be applied in almost every industry to various business processes [21]. Digital transformation is a process driven by digital technologies and plays an important role in meeting the goals of environmental, economic and social sustainability. If companies interact with digital technologies and use digitalization in the areas of environmental sustainability, then the process of green digital transformation occurs in companies and digital technologies are referred to as green, resp. sustainable.

We did not find a definition of green digital transformation and green technology from the available sources, and therefore we propose the following definitions:

- Green digital transformation is the implementation of digitalization and interaction of green technologies into business processes, activities, products and models, when the company becomes environmentally sustainable.

- Green technology represents the integration and subsequent use of digital technologies to innovate business processes and are used in the field of sustainable environmental development of the organization.

Based on the analyzed documents from the European Commission, we can confirm that it is determined to realize its main ambition, which is to convert the states and businesses of the European Union through a green and digital transformation. This is also confirmed by the European Green Digital Coalition (EGDC), which is made up of the 24 states of the European Union together with Norway and Iceland, where the states signed a declaration on accelerating the use of green technologies for the benefit of the environment and thus committed to key digital initiatives. EGDC will not only help the technology sector to become more sustainable, circular and zero polluters, but will also support the sustainability goals of other priority sectors such as energy, transport, agriculture and construction, while contributing to an innovative, inclusive and resilient society [22-27].

The application and use of digital technologies can have a positive impact on companies in: saving money, reducing greenhouse gas emissions, identifying products offering excellent energy efficiency, reducing the cost of consumables and public services, increasing profits, taking business to the next level, facing competition with new ones technologies, the offer of new services, the simplification of the flow of operations, innovation, the increase in organizational performance, the transition from the old business approach to the digital, the development and creation of new skills and the indirect maintenance of labor markets. On the other hand, they also have negative impacts and impacts on organizations in the areas of environment and sustainability. Restricting digital technologies and innovation would not be an environmental solution, as digital technologies have higher benefits than consequences and protect the environment and contribute to sustainability in the areas concerned. Elimination of harmful effects could be avoided by assessing the energy efficiency of digital technologies according to traditional parameters such as: functionality, security, scalability and accessibility, which would also include green practices and targets as performance monitoring criteria. However, the potential of digital technologies to contribute to addressing environmental issues far exceeds the unintended negative effects it can cause. Innovations in data generation and analysis combined with Artificial Intelligence (AI) and advanced robotics, as well as cloud computing, have opened the door to many positive impacts on sustainability.

\section{Acknowledgement}


The paper was elaborated within Project of young teachers, researchers and doctoral students in full-time study No. I-21-105-00 Digitalization of enterprises and application of digital technologies in business processes in proportion $100 \%$.

\section{References}

1. J. Reis, M. Amorim, N. Melão, Y. Cohen, M. Rodrigues, Digitalization: A Literature Review and Research Agenda. In: Proceedings on 25th International Joint Conference on Industrial Engineering and Operations Management IJCIEOM, IJCIEOM 2019. Lecture Notes on Multidisciplinary Industrial Engineering. Springer, Cham, 443-456 (2020)

2. J. S. Brennen, D. Kreiss, Digitalization, The International Encyclopedia of Communication Theory and Philosophy, John Wiley \& Sons, Inc., New Jersey, USA. (2016)

3. T. Ritter, C. L. Pedersen, Digitization capability and the digitalization of business models in business-to-business firms: Past, present, and future, Industrial Marketing Management, 86, 180-190 (2020)

4. P. M. Bican, A. Brem, Digital Business Model, Digital Transformation, Digital Entrepreneurship: Is There A Sustainable "Digital"?. Sustainability, 12, 5239 (2020)

5. I. Linkov, B. D. Trump, K. Poinsatte-Jones, M.-V. Florin. Governance Strategies for a Sustainable Digital World. Sustainability, 10, 440 (2018)

6. S. Fielke, B. Taylor, E. Jakku, Digitalisation of agricultural knowledge and advice networks: A state-of-the-art review. Agricultural Systems, 180, 102763 (2020)

7. K. Feroz, H. Zo, A. Chiravuri, Digital Transformation and Environmental Sustainability: A Review and Research Agenda. Sustainability, 13, 3, 1530 (2021)

8. J. W. Ross, C. M. Beath, M. Mocker, "Creating Digital Offerings Customers Will Buy,". MIT Sloan Management Review, 61, 64-69, (2019)

9. European Environment Agency (EEA) (2019). The European Environment State and Outlook 2020. Luxembourg: Publications Office of the European Union, 2019. ISBN 978-92-9480-115-9. Available at: <doi: 10.2800/48006>

10. COM(2021), DECLARATION of the European Green Digital Coalition Members "In support of the Green and Digital Transformation of the EU". Available at: $<$ https://bit.ly/2Q6XwEd > [Accessed 19-03-2021]

11. European Council, Council of the European Union (2020). Digitalisation for the Benefit of the Environment. Available at: $<$ https://data.consilium.europa.eu/doc/document/ST-13957-2020-INIT/en/pdf> [Accessed 11-12-2020]

12. European Council, Council of the European Union (2020). Infographic Multiannual financial framework 2021-2027 and Next Generation EU. Available at: <https://www.consilium.europa.eu/en/infographics/mff2021-2027-ngeu-final/> [Accessed 21-04-2021]

13. European Council, Council of the European Union (2021). Digital Europe Programme and repealing Decision (EU) 2015/2240. Available at: $<$ https://eurlex.europa.eu/legalcontent/EN/TXT/PDF/?uri=CONSIL:ST_6789_2020_REV_1\&from=EN> [Accessed 18-03-2021]

14. T. M. Wut, D. Lee, W. M. Ip, S. W. Lee, Digital Sustainability in the Organization: Scale Development and Validation. Sustainability, 13, 3530 (2021)

15. C.-T. Tseng, S. S. C. Shang, Exploring the Sustainability of the Intermediary Role in Blockchain. Sustainability, 13, 1936 (2021) 
16. P. Gregori, P. Holzmann, Digital sustainable entrepreneurship: A business model perspective on embedding digital technologies for social and environmental value creation. Journal of Cleaner Production, 272, 122817 (2020)

17. D. Lepore, A. Micozzi, F. Spigarelli, Industry 4.0 Accelerating Sustainable Manufacturing in the COVID-19 Era: Assessing the Readiness and Responsiveness of Italian Regions. Sustainability, 13, 2670 (2021)

18. H. S. Sætra, AI in Context and the Sustainable Development Goals: Factoring in the Unsustainability of the Sociotechnical System. Sustainability, 13, 1738 (2021)

19. D. Melissa, S. Evans, F. Tonelli, Digitalization Technologies for Industrial Sustainability. Procedia Manufacturing, 33, 264-271 (2019)

20. PWC, How can enable a sustainable future. Available at: $<$ https://www.pwc.co.uk/services/sustainability-climate-change/insights/how-aifuture-can-enable-sustainable-future.html $>$ [Accessed 05-05-2021] (2021)

21. O. Mulhern, Artificial Intelligence: Can it help achieve Environmental Sustainability? $\quad<$ https://earth.org/data_visualization/ai-can-it-help-achieveenvironmental-sustainable $>(2021)$

22. $\operatorname{COM}(2019) 640$ final, The European Green Deal. Available at: $<$ https://ec.europa.eu/info/sites/default/files/european-green-dealcommunication_en.pdf $>$ [Accessed 11-12-2019]

23. $\operatorname{COM}(2020) 102$ final, A New Industrial Strategy for Europe. Available at: $<$ https://eur-lex.europa.eu/legalcontent/EN/TXT/PDF/?uri=CELEX:52020DC0102\&from $=\mathrm{EN}>$ [Accessed 10-032020]

24. $\operatorname{COM}(2020) 442$ final, The EU budget powering the recovery plan for Europe. Available at: <https://eur-lex.europa.eu/resource.html?uri=cellar:4524c01c-a0e611ea-9d2d-01aa75ed71a1.0003.02/DOC_1\&format=PDF $>$ [Accessed 27-05-2020]

25. $\operatorname{COM}(2020) 456$ final, Europe's moment: Repair and Prepare for the Next Generation. Available at: <https://eur-lex.europa.eu/legalcontent/EN/TXT/PDF/?uri=CELEX:52020DC 0456\&qid=1620598808861\&from $=\mathrm{EN}>$ [Accessed 27-05-2020]

26. $\operatorname{COM}(2020) 652$ final, Proposal for a Decision of the European Parliament and of the Council on a General Union Environment Action Programme to 2030. Available at: <https://www.slov-lex.sk/legislativne-procesy/SK/LPEU/2020/637> [Accessed 14-10-2020]

27. Official Journal of the European Union (2020). Council conclusions on shaping Europe's digital future $(2020 / \mathrm{C} 202 \mathrm{I} / 01)$. Available at: <https://eurlex.europa.eu/legalcontent/EN/TXT/PDF/?uri=OJ:C:2020:202I:FULL\&from=ET> [Accessed 16-062020] 